\title{
Brief Paper:
}

\section{The Trend of Blockchain in Vietnam and Its Implications for ROK}

\author{
Hanbum (Albert) Cho ${ }^{1}$, Jack Choi ${ }^{2}$, Huy-Nam Nguyen ${ }^{3 *}$, Thi-Hong Nguyen ${ }^{4 * *}$
}

\begin{abstract}
Bitcoin and blockchain are often making headlines not only on TV or media but also among the public in today's society. These technologies have been developed after the risk of the centralized financial system came to the fore during the 2007 global financial crisis. Since then, an anonymous inventor called Satoshi Nakamoto penned the bitcoin white paper where a blockchain-based reference implementation was introduced. Bitcoin was able to achieve unprecedented growth by positioning itself as one of the top global currencies in terms of market capitalization after five years since its development. The pace of Vietnam's economic development is notably fast among Asian nations, while the nation was expected to be a Southeast Asian blockchain hub but they have banned virtual currency trading recently. However, they've also designated the State Bank of Vietnam (SBV) as a responsible agency for the research of blockchain-based cryptocurrencies, the construction of a service ecosystem, and their test operations. The fast-growing economy, increasing number of smartphone users, and the Vietnam government's support policies for startups substantiate these efforts. Therefore, this paper attempts to study the current status of Vietnam's blockchain technology that has been considered to be the center of blockchain systems right behind Singapore, and its implications for Korean companies.
\end{abstract}

Key Words: Blockchain Trend, Vietnam's Blockchain, Vietnam.

\section{INTRODUCTION}

Blockchain refers to a chain where a series of blocks are being connected [1]. More specifically, it a distributed data storage technology that chains the data stored in each block to copy and store them in large numbers of computers simultaneously, which is also called public ledger technology [2]. According to the thesis 'Bitcoin: P2P Electronic Cash System', Bitcoin was defined as an electronic cash exchanged between transacting parties only to prevent double payment by using a P2P network. To put it simply, it is a sort of database we often use in our daily lives. This technology is emerging as a core technology that can improve data reliability and stability as the data cannot be forged or altered [3-4].

As of now, blockchain is mainly used for virtual currencies and ICOs, where financial transactions are stored in each block and verifiable by all participating users. The contents are compared for each transaction to prevent any risk of forgery or alteration. This technology can be applied to wide range of businesses such as online/electronic banking, digital certification, shipment /distribution tracking, P2P loans, artwork authentication, counterfeit money identification, electronic voting, issuance of electronic residency, ride-sharing, real estate registration, management of shared medical records between hospitals, among other areas where high reliability is required. Primarily, blockchains are divided into public and private platforms: the former is open to all people for their participation. Most notable examples include Bitcoin and Ethereum. The latter is operated by agencies or companies and can be used by people with prior permission only. This limits the number of participants so that the system works relatively faster.

Currently, Vietnam enjoys the fastest economic growth among the Asian countries and is expected to become a Southeast Asian blockchain hub. Their fast-growing economy and rapidly increasing supply of smartphones along with government's startup supporting policies have backed up such an assessment of the nation becoming a hub of the blockchain ecosystem right behind Singapore.

Manuscript received September 6, 2021; Revised September 23, 2021; Accepted September 26, 2021. (ID No. JMIS-21M-09-030) Corresponding Author (**): Thi-Hong Nguyen, Coordinator of VK Technological Exchange Seminar at Thanh Hoa, Thanh Hoa, Socialist Republic of Vietnam, thuhong2903@ hotmail.com

Co-Corresponding Author (*): Huy-Nam Nguyen, CFO of VK Technological Exchange Seminar at Thanh Hoa, Thanh Hoa, Socialist Republic of Vietnam, CFOofHNVK@gmail.com

${ }^{1}$ First Author: Hanbum (Albert) Cho, Patent Agent of VK Technological Exchange Seminar at Thanh Hoa, Thanh Hoa, Socialist Republic of Vietnam, hanbumllp@gmail.com

${ }^{2}$ Co First Author: Jack Choi, Co CEO of VK Technological Exchange Seminar at Thanh Hoa, Thanh Hoa, Socialist Republic of Vietnam, anaJackchoi@gmail.com 
According to General Statistics Office of Vietnam (GSOV), the rate of economic growth in 2018 (pre-Covid-19 outbreak) was $6.7 \%$, reducing the nation's poverty rate to $3 \%$ while improving health and educational standards. However, the proportion of adults who have bank accounts was $31 \%$ and it is expected that about $40 \%$ of their population will have smartphones by 2021, which means that there is a great growth potential for financial and IT sectors.

\section{BACKGROUND KNOWLEDGE}

The Blockchain appeared in the New York Times in 2013 [5], along with Beck Coin, who was also named Oxford's "Word of the Year" by the Oxford Dictionary [6]. Bitcoin started with Bitcoin (A Peer-to-Peer Electronic Cash System) published by Satoshi Nakamoto in October 2008, and since January 2009 [7-8], It is an online virtual currency that freely trades between nodes in a P2P way without an intermediary [9]. This security technology designed to safely store and use electronic money called 'bitcoin' utilizes the Blockchain technology [10].

The Blockchain is also called a public transaction book. It is a technology that prevents double payment that can occur in financial transactions and can not be tampered with [11]. It has become a core technology of Pintech in Republic of Korea [12]. The bitcoin is the tip of the iceberg, which is an application example of a Blockchain application. Still, the public has been underestimating the Blockchain by concentrating only on the tip of the iceberg called Bitcoin [13]. Recently, however, we are paying attention to the possibility of expanding and expanding the Blockchain that is the underlying platform technology [14]. Unlike us, which is still in the early stages of business integration, overseas business is a new business platform that combines technologies such as ICT (Information and Communication Technology), IoT (Internet of Things). However, current passwords have difficulties in linking them to real-life situations.

\section{THE TREND AND POTENTIAL OF BLOCKCHAIN IN VIETNAM}

A global media outlet Forbes forecasted that an appbased blockchain financial services would appear in Vietnam. The Vietnamese government set on promoting venture companies will also be a driving force for developing blockchain technology. As one of their science and technology promotion plans, the Technology Transfer Act came into effect in July 2017 and expecting that their support would focus on the IT field/sector, which have been relatively slow in development there, many colleges across Vietnam started to develop strong talent and competency in technology by newly establishing blockchain-related courses in the same year. For the public at large, their interest in blockchain is quite high with over 2,000 people appearing at the Blockchain Week event held in Ho Chi Minh City in March 2016 [15].

The host of the event Infinity Blockchain Lab was cited in Forbes saying, "A Vietnamese venture company having strong programming skills and a dynamic community is developing an app associated with crytocurrencies," and added, "Such effort will continue in the long term and publicize the surge of Vietnam in the blockchain industry." Vietnam does not stop here. Based on trading between Korea and Vietnam, for example, HSBC successfully provided an $\mathrm{L} / \mathrm{C}$ issuance on blockchain-based sales to facilitate commerce between a multi-national chemical company (INEOS Styrolution) and a Vietnamese plastic processing company (Duytan) [16].

This was the first transaction between these two countries where a single application called Boltron was used for the process. Boltron is a blockchain-based trade finance platform digitalizing the existing L/C-based process. The $\mathrm{L} / \mathrm{C}$ opened by Duytan was notified to INEOS Styrolution in real time, while HSBC participated as both the opening bank and the negotiating bank.

Besides other cases, Korea's Blockcloud established a strategic alliance with Vietnam's largest blockchain community VIC Group. VIC Group has over 100,000 members with great influence on the blockchain industry. With the support of VIC, Blockcloud is attempting to expand their influence in Vietnam. Furthermore, both companies agreed to jointly host a variety of exchange programs to attract more technicians. VIC Group is a community established in 2016 and has over 100,000 crytocurrency users or traders in addition to mining and developer communities, including the largest user-based index software company Vicion. In contrast, Republic of Korea's Blockcloud plans to grow further through this alliance [17-18].

Meanwhile, the Japanese company SBI Holdings entered into an agreement with the Vietnamese company FPI, which is the largest software developer and system operation \& maintenance consulting firm in Vietnam, for setting up a joint-venture company Utop, responsible for the construction of a blockchain-based point system requiring a joint investment of $¥ 300,000,000$. Both companies are developing an enterprise blockchain platform 'akaChain' and Utop's goal is to allow point acquisition or product purchase at retail stores. FTP's Director Truong Gia Binh explained, "The 4th industrial revolution brings with it the most suitable business models to Southeast Asian nations especially Vietnam, where social infrastructure is relatively weak. Although there are many new methods that utilize blockchain technology 
emphasizing a 'Cashless Society', it is not easy to transform or create renewed infrastructures so that Southeast Asian countries with weak social infrastructures including Vietnam can easily adopt them," and added that he hoped, "Many new and innovative business models will be able to grow rapidly among these countries in the future under the $4^{\text {th }}$ industrial revolution; and considering all the on-going development, we were able to conclude that the use of blockchain technology would efficiently prevent many lingering issues and persistent negative impacts on society, so these projects are becoming so urgent now as emerging technologies get susceptible to misuse and causing damage. To address the clear hurdles to overcome as Vietnam's economy is still heavily weighted toward agriculture, a plan to improve the distribution network system/ infrastructure and reduce transaction costs by applying blockchain technology to the agricultural sector is currently in the works." Then, he further stated, "The authors of Blockchain Revolution Don and Alex Tapscott also claimed in their interview with Mckinsey and Company that it is possible to help farmers by documenting the land ownership using blockchain; and blockchain technology can reduce poverty by promoting the digital economy. So we expect to see a more safe and comfortable world through our future projects and further advance blockchain market."

Thus, all the trades on the cryptocurrency exchanges including Binance, Coinbase, Okex, Remitano, and Bittrex will not be protected by law and the losses are borne as a personal liability in full.

\section{KOREAN BLOCKCHAIN COMPANIES ADVANCING TO VIETNAM HAVING YOUNG BUT HIGHLY POTENTIAL MARKET}

Vietnam is rapidly emerging as a major partner of the Korea's blockchain projects. According to the blockchain industry, Vietnam has become an attractive country for the domestic companies as overseas expansion is a key driver for their success [19]. The population of Vietnam is over 100 million and their average age still remains in their $30 \mathrm{~s}$, achieving over $6 \%$ economic growth annually. The nation is a young and dynamic one. Also, Vietnam is a nation accounting for large investments and transactions in cryptocurrencies next to the U.S., China, Russia, S. Korea, and Japan.

Being the first among the Korean companies, the blockchain social media platform service company NEEOApps recently opened a global cryptocurrency exchange EXVINA allowing the Vietnamese currency VND to be used after establishing a corporation to enter the East Asian market.
The exchange targets the Vietnamese coin market through a technical tie-up with a Korean cryptocurrency exchange. A company official explained, "The exchange service system's performance can be largely affected by the transaction volumes or changes, and so a safe and flexible system environment has been constructed for the EXVINA's system," adding that, "This system has a powerful monitoring system for core financial services such as deposits \& withdrawals, remittances, and wire transfers while satisfying the requirements of the financial regulators initiating a separate log-in in case of any abnormal transactions."

Meanwhile, EXVINA adapted the stable system designed by financial security experts. Additionally, other than the exchange service, they added a game-like reward system along with a variety of reward features. This operation method of increasing customers' asset values is patent pending.

Vin Crypto is a Vietnamese specialized investment company organized by financial and blockchain experts and despite their short history, their influence in the Vietnam's blockchain industry is spreading rapidly [19-20]. The recent investment agreement was made at their Hanoi HQ with major executives of contracting parties; thus, with this investment, Vin Crypto will play a major partner role in the expansion of the 'Vinple Project' in the Vietnam." According to a Vin Crypto official, based on reviewing Vinple platform's growth potential and future value in detail, there is enough investment value and opportunity for the project's global expansion, so they will actively accelerate the platform to firmly settle in Vietnam by connecting it with business networks.

Symax Media (Vietnam) manages the Sigmachain's (ROK) total blockchain platform project 'Futurepia' currently underway in Vietnam. They are responsible for marketing, promotion, networking, and listing on the crytocurrency exchange. Led by Symax, Futurepia's first released application (DApp) SNAC (a blockchain social media messenger service) will be launched next month. Subsequently, with the technical support from Sigmachain, a hit Dapp that uses SNAC coins as payment in a variety of areas such as sound source/photos/photos/webtoons/gaming services will be introduced in stages.

\section{CONCLUSION}

The size of Vietnam's FinTech market in 2017 (prior to the COVID-19 outbreak) was approx. USD 4.4 billion and is subdivided into electronic payments, P2P financial services, blockchain, etc. Observing the regulations associated with the FinTech business and industry, the 
Central Bank of Vietnam announced a revision in 2016 to reduce the cash payment rate to $10 \%$ by 2020 . Then, in 2018, the Vietnam government led by SBV and NAPAS established the FinTech Steering Committee to support and advance the FinTech industry and market. Meanwhile, Financial Supervisory Service of Korea entered into a FinTech industry business agreement with SBV in 2018 and announced a plan to strengthen cooperation with ASEAN nations in the following year.

Woori Financial Group established the Hanoi Digital Innovation Lab in 2019 to support startups who wish to do business in Vietnam, and provides consulting, networking, and market analysis services.

Shinhan Financial Group established a FinTech lab center called Future's Lab to support Vietnamese startups, and provides back-office support services and mentoring for 11 startups since 2019 .

\subsection{Electronic Payments}

Electronic payments are a convenient and fast payment method that transpires online or via mobile devices and holds the largest market position in the Vietnamese FinTech industry in terms of the number of involved companies and investment size. In 2019, the Softbank Vision Fund and GIC made a USD 300 million investment in VNLIFE, the mother company of VNPAY, while Warburg Pincus invested USD 100 million in Momo [1-2].

Meanwhile, according to the market survey company FT Confidential Research, Momo and ZaloPay are the two most famous e-wallet companies in Vietnam. Prior to the pandemic, Momo was working in partnership with stores across Vietnam as well as 15 banks, and had about 10 million users. In contrast, ZaloPay is an e-wallet service of the IT firm VNG and links with the messenger app Zalo developed by VNG itself. The number of users is estimated at over 100 million.

$\mathrm{P} 2 \mathrm{P}$ financial services refer to a service that links loans and investments between individuals on the P2P platforms that play the role of the existing financial institutions. Tima is the largest P2P loan platform and has about 40,000 lenders and 4.3 million borrowers. The number of their loan applications has reached up to 7.3 million cases valued at USD 3.8 billion.

\subsection{Electronic payments (e-Payment)}

Electronic payments (e-Payment) are basically divided into the e-Wallet and payment gateway services, or a hybrid model. E-wallet is a payment method where a non-cash payment is made on e-commerce sites or online stores through one's own e-Wallet app/account and does not require a bank account. In contrast, payment gateway is an e-Payment platform that makes electronic payments through a bank account that the user must have access to. The hybrid model performs these two types of payments on the same platform. The typical e-Wallet services available in Vietnam are MoMo, ZaloPay, ViettelPay, Moca, Airpay and Samsung Pay, and the payment gateway services are Smartlink, 123 Pay, and One Pay. Payoo, NganLuong.vn, BAOKIM.VN, and VNPAY are hybrid models. The growth rates in the number of downloads for major e-Wallet apps in 2021 are shown in Fig. 1.

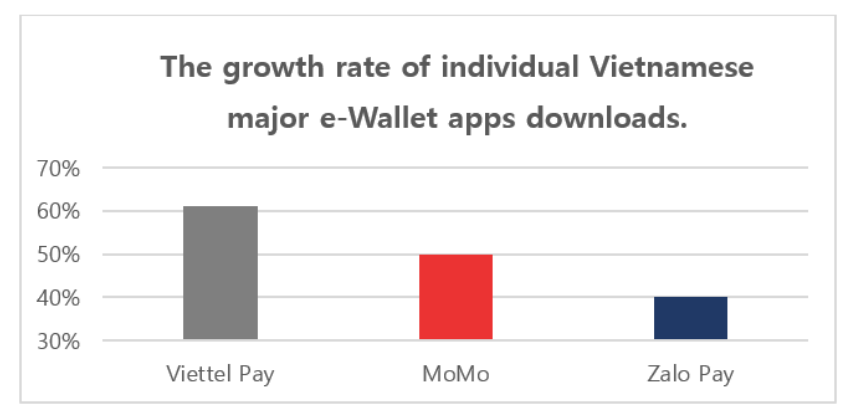

Fig. 1. The download growth rate of Vietnamese major e-Wallet apps.

Meanwhile, according to Economy SEA 2020, a joint survey conducted by Google. TEMASEK · BAIN \& Co., the size of the Vietnamese digital economy in 2020 was USD 14 billion (an increase of $16 \%$ compared with last year) and expected to reach 52 billion by 2025 , which is an increase of $29 \%$ compared with 2020.

As shown in Fig. 2, the size of the Vietnam's e-Payment market in 2020 was USD 8.6 billion and expected to grow rapidly by 2024 , reaching up to 14.9 billion. Reports also showed that payments via mobile phones accounted for approx. USD 1.6 billion in the same year and are expected to increase to USD 3.7 billion by 2024 .

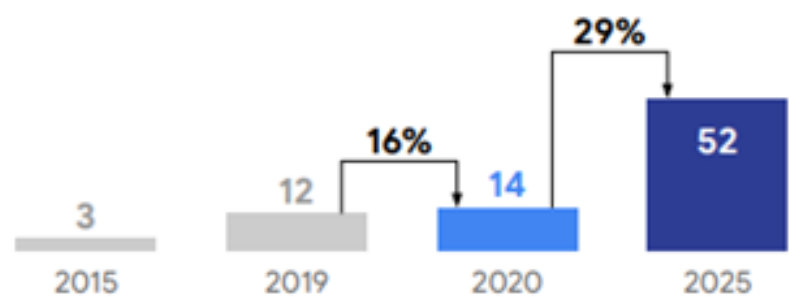

Fig. 2. The Size of the Vietnamese Digital Economy.

Fig. 3. shows the types of payment items and their proportions for each e-Wallet, where the proportion of settlement payments using mobile phones was the highest, while the payments made at stores with e-Wallets stayed at the bottom. 


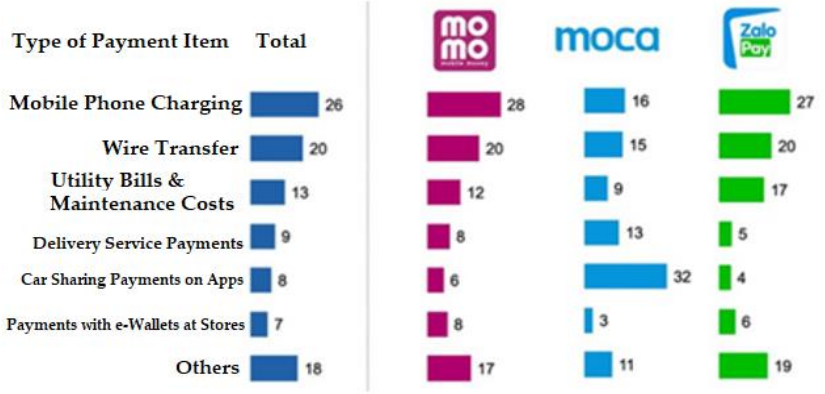

Fig. 3. The Types of Payment Items.

Lastly, Fig. 4 shows the result obtained by Wordclouding Vietnamese e-Wallet (blockchain) companies. Fig. 4(a) shows Wordclouding Vietnamese e-Wallet. Also, Fig. 4(b) shows wordclouding result.

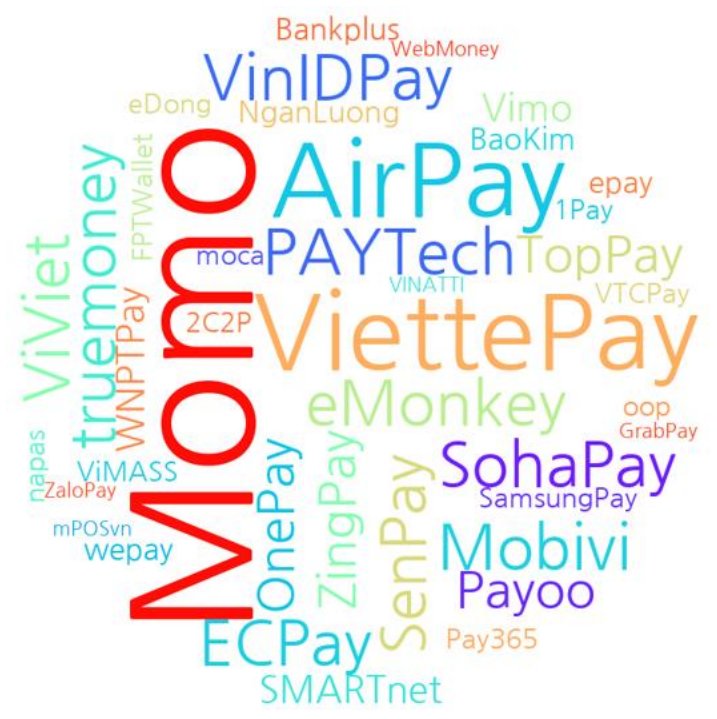

(a) Wordclouding Vietnamese e-Wallet

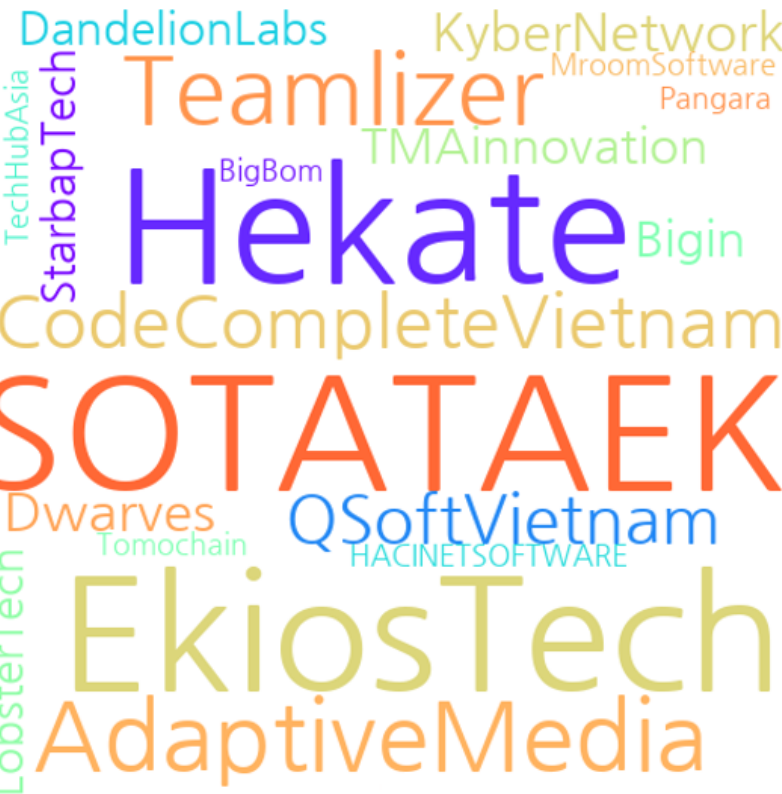

(b) Wordclouding Blockchain Companies

Fig. 4. Wordclouding Result.

\subsection{Blockchain and cryptocurrencies}

Blockchain refers to a distributed data processing technology that stores all the transaction data of the users participating in a P2P network. The Vietnam's blockchain providers include Tomochain, Kyber Network, Big Bom, etc. Almost all of the cryptocurrencies traded in the other countries are also being traded in Vietnam and according to experts, the number of people investing in those currencies has reached over one million in 2021 and is expected to increase approx. 30 times by 2030 .

As of now, no regulations on digital currencies like crytocurrencies exist under Vietnamese legal framework, and so all the transactions made at the exchanges such as Binance, Coinbase, Okex, Remitano, Bittrex, etc. are not protected by law. Therefore, traders or investors must bear full liability for losses themselves. The Vietnamese government still defines virtual currency trading as illegal despite a clear definition of virtual currencies is already accepted, while cryptocurrencies such as Bitcoin are being actively traded globally and overseas investors are profiting from transaction platforms.

\section{CONCLUSION}

Due to the worldwide popularity of Bitcoin trading, the Vietnamese government is reluctant to clearly define virtual currency trading as illegal. However, they ordered their financial regulators to conduct research on the technologies relevant to the virtual currencies. According to the VN Express's $2^{\text {nd }}$ quarter article in 2021, the government ordered their central bank to conduct research and test operating blockchain-based virtual currencies. Their actions show that they view blockchain technology as one of the main emerging core technologies that needs to be studied.

Vietnamese Prime Miniter Pham Minh Chinh has designated SBV as a responsible agency for researching, constructing a service ecosystem, and test operating the blockchain-based virtual currencies until 2023. This will be carried out as part of development strategy of electronic government for the construction of digital government. They have decided that blockchain is a core technology of the $4^{\text {th }}$ industrial revolution characterized by cryptocurrencies such as Bitcoin, etc. Therefore, SBV will be primarily focusing on the development and application of open-source and open-platforms to accelerate the construction of a digital government, the expansion of a digital ecosystem to promote digital technology companies' participation in the digital economy or society, as well as research on core technologies including blockchain, AI, big data, QR code, virtual/augmented reality, etc. Indeed, all of 
these areas mark the many opportunities for globally focused IT companies.

\section{REFERENCES}

[1] Socialist Republic of Vietnam Government, "The 2018 trend and prospect of Vietnamese mobile payment industry," 2018.

[2] Binh Minh Nguyen, Thanh-Chung Dao, Ba-Lam Do, "Towards a blockchain-based certificate authentication system in Vietnam," PeerJ Computer Science, vol. 6, pp. 1-27, 2020.

[3]http://it.chosun.com/site/data/html_dir/2019/02/27/201 9022701484.html (accessed on 27 August 2021).

[4]https://steemit.com/gate/@gateioexchange/53feci (accessed on 27 August 2021).

[5]https://www.dailycoinews.com/dailycoinews/article/rea d.do? articleNo=3138\&lang=kr (accessed on 27 August 2021).

[6] Yan Chen, "Blockchain tokens and the potential democratization of entrepreneurship and innovation," SSRN, pp.12-13, 2017.

[7] Y Nir Kshetri, "Blockchain's roles in meeting key supply chain management objectives," International Journal of Information Management, pp. 80-82, 2018.

[8] Alexander Savelyev, "Copyright in the Blockchain era: Promises and challenges," Computer Law \& Security Review, 2018.

[9] Thanh Chung Dao, Binh Minh Nguyen, Ba Lam Do, "Challenges and strategies for developing decentralized applications based on blockchain technology," in proceedings of International Conference on Advanced Information Networking and Applications, Japan, pp. 952-962, March 2019.

[10] Thi Thao Ha, Cong Phap Huynh, "Towards a Land Records Administration Model in Vietnam using Blockchain Technology," 2020.

[11] Seong-Kyu Kim, Jun-Ho Huh, "Autochain platform: expert automatic algorithm Blockchain technology for house rental dApp image application model," EURASIP Journal on Image and Video Processing, 2020(1), pp. 1-23, 2020.

[12] Nguyen Hoang Phuong, "Blockchain-an indispensable development trend of logistics industry in Vietnam: Current situation and recommended solutions," International Journal of e-Navigation and Maritime Economy, vol. 13, pp. 14-22, 2019.

[13] Jun-Ho Huh, Seong-Kyu Kim, "Verification plan using neural algorithm blockchain smart contract for secure P2P real estate transactions, " Electronics, vol. 9, no. 6, pp. 1-25, 2020.

[14] Seong-Kyu Kim, Jun-Ho Huh, "Blockchain Agreement for Self-identification of Online Test
Cheating: Improvement of Algorithm Performance," in proceedings of the 20-th IEEE International Conference on Control, Automation and Systems, Busan, pp. 1124-1133, 2020.

[15] Hai Yen Nguyen, "Fintech in Vietnam and Its Regulatory Approach," Regulating FinTech in Asia, pp. 115-138, 2020.

[16] Mai Đuc Trung, Nguyen Duc Dinh Nghia, Nguyen Quoc Thinh, Hoang Minh Tung, Do Van Long, Trang Hong Son, Huynh Tuong Nguyen, Quan Thanh Tho, "An overview of blockchain applications and its impact to Vietnam context," Publishing House for Science and Technology, pp. 28-35, 2019.

[17] S. S. Kim, W. J. Jang, H. T. Phuong, J. J. Lee, G. Y. Gim, "Comparison of intention of using blockchain technology in Korea and Vietnam," Asia Life Sciences, 2019, pp. 69-82.

[18] Nguyen Quoc Hung, Thai Kim Phung, Phan Hien and Dang Ngoc Hoang Thanh, "AI and Blockchain: potential and challenge for building a smart E-Learning system in Vietnam," IOP Conference Series: Materials Science and Engineering, vol. 1022, no. 1, 2021.

[19] Hoang, Hien Do, Phan The Duy, Van-Hau Pham, "A Security-Enhanced Monitoring System for Northbound Interface in SDN using Blockchain," in Proceedings of the Tenth International Symposium on Information and Communication Technology (SoICT 2019), pp. 197-204, 2019.

[20] Tran Thien Vu, Hue Hoang Hong Trinh. "Blockchain technology for sustainable supply chains of agri-food in Vietnam: a SWOT analysis," Science \& Technology Development Journal-Economics-Law and Management, vol. 5, no. 1, pp. 1278-1289, 2021.

[21] Ngoc-Hoa Nguyen, Binh Minh Nguyen, Thanh-Chung Dao, Ba-Lam Do, "Towards Blockchainizing Land Valuation Certificate Management Procedures in Vietnam," in Proceedings of IEEE 2020 RIVF International Conference on Computing and Communication Technologies (RIVF), 2020. 